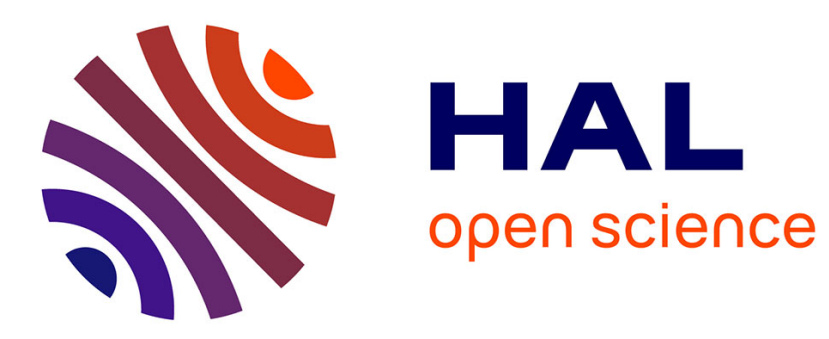

\title{
Olefin metathesis transformations in thermomorphic multicomponent solvent systems
}

Shilin Huang, Hallouma Bilel, Fethy Zagrouba, Naceur Hamdi, Christian Bruneau, Cédric Fischmeister

\section{- To cite this version:}

Shilin Huang, Hallouma Bilel, Fethy Zagrouba, Naceur Hamdi, Christian Bruneau, et al.. Olefin metathesis transformations in thermomorphic multicomponent solvent systems. Catalysis Communications, 2015, 63, pp.31-34. 10.1016/j.catcom.2014.09.009 . hal-01114562

HAL Id: hal-01114562

https://hal-univ-rennes1.archives-ouvertes.fr/hal-01114562

Submitted on 2 Jul 2015

HAL is a multi-disciplinary open access archive for the deposit and dissemination of scientific research documents, whether they are published or not. The documents may come from teaching and research institutions in France or abroad, or from public or private research centers.
L'archive ouverte pluridisciplinaire HAL, est destinée au dépôt et à la diffusion de documents scientifiques de niveau recherche, publiés ou non, émanant des établissements d'enseignement et de recherche français ou étrangers, des laboratoires publics ou privés. 


\title{
Olefin Metathesis Transformations in Thermomorphic Multicomponent Solvent Systems
}

Shilin Huang, ${ }^{\mathrm{a}}$ Hallouma Bilel, ${ }^{\mathrm{a}, \mathrm{b}}$ Fethy Zagrouba, ${ }^{\mathrm{b}}$ Naceur Hamdi, ${ }^{\mathrm{b}}$ Christian Bruneau, ${ }^{\mathrm{a}}$ Cédric Fischmeister* a

${ }^{a} U M R$ 6226-CNRS-Université de Rennes1, Institut des Sciences Chimiques de Rennes. Organometallics: Materials and Catalysis. Centre for Catalysis and Green Chemistry. Campus de Beaulieu, 35042 Rennes Cedex, France.

cedric.fischmeister@univ-rennes1.fr

${ }^{\mathrm{b}}$ University of Carthage, Higher Institute of Sciences and Technology of Environment of Borj Cedria, B.P. 1003, 2050, Hammam-Lif, Tunisia.

\begin{abstract}
Homogeneous catalysis is a major actor of modern chemistry with a growing impact on clean and sustainable chemical processes. However, for many industrial applications of homogeneously catalyzed reactions, an easy separation and recovery of the catalyst should be guaranteed. Temperature-dependent multicomponent solvent systems (TMS) have been evaluated in ruthenium catalyzed olefin metathesis transformations. Propylene carbonate was found a suitable solvent for the ruthenium catalyzed ring-closing and cross-metathesis transformations of a variety of substrates including renewable fatty esters. The potential of a TMS system consisting of propylene carbonate/ethyl acetate/cyclohexane was then evaluated in the cross-metathesis of the renewable methyl 10-undecenoate with methyl acrylate and acrylonitrile.
\end{abstract}

\section{Introduction}

Olefin metathesis is a powerful synthetic tool that has found a growing interest in the organic and polymer synthesis community.[1-3] As for many other catalytic transformations, posttreatment of the reaction media for catalyst/product separation is an important concern in particular when high catalyst loadings are required in the last or late stage of a synthetic sequence. Despite important progress in catalyst performances, [4,5] the vast majority of ruthenium catalyzed transformations usually requires catalyst loadings of $1 \mathrm{~mol} \%$ or higher as for the synthesis of macrocycles.[6] Consequently, several methods or processes have been designed for catalyst/product separation aimed at decreasing metal contamination of the final products[7] and in some cases for catalyst recycling[8] in particular using non-conventional solvents.[9-13] Over the last decade we have been investigating several processes for catalyst/product separation [9-10,14,15] and we have also searched for alternative greener solvents for olefin metathesis transformations. In particular, the findings that dimethyl carbonate was a suitable solvent for olefin metathesis transformations [16] prompted us to investigate the potential of temperature-dependent multicomponent solvent systems (TMS) using dialkyl carbonates as the polar phase. Since the first reports on thermomorphic catalysts by Bergbreiter in 1998 [17] and on temperature-dependent multicomponent solvent systems by Behr in 1999,[18] TMS systems have proven their interest and potential in a broad range of homogeneously catalyzed transformations.[19-25] To the best of our knowledge, only few studies on ruthenium-catalyzed olefin metathesis transformation in TMS system and thermomorphic polymer supported catalysts have been reported [26-28]. Herein, we present our results on olefin metathesis transformations in TMS system employing propylene carbonate as the polar phase. 


\section{Results and Discussion}

Olefin metathesis transformations have been and are still essentially conducted in solvents with environmental and health issues, typically toluene or dichloromethane (DCM). Since 2008, we have shown that dimethyl carbonate (DMC) could be used as a greener and more environmentally acceptable solvent in metathesis transformations.[16, 29, 30] As opposed to DMC which is miscible with alkanes $(\mathrm{C} 5, \mathrm{C} 6, \mathrm{C} 7)$ at room temperature, propylene carbonate (PC) is a solvent that can be used as the polar component of TMS systems. However, propylene carbonate displays very different physico-chemical properties from dimethyl carbonate (PC, $\varepsilon=64.8, \mu=4.94 \mathrm{D}, \mathrm{DMC}, \varepsilon=3.1, \mu=0.9 \mathrm{D}),[31]$ hence we first investigated the compatibility of propylene carbonate with a series a benchmark ring-closing and crossmetathesis reactions using two commercially available ruthenium catalysts (Scheme 1).
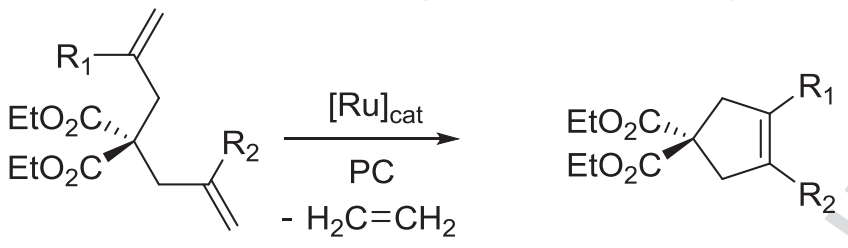

$$
\begin{aligned}
& 1 \mathrm{R}_{1}=\mathrm{R}_{2}=\mathrm{H} \\
& 2 \mathrm{R}_{1}=\mathrm{Me}, \mathrm{R}_{2}=\mathrm{H} \\
& 3 \mathrm{R}_{1}=\mathrm{R}_{2}=\mathrm{Me}
\end{aligned}
$$

$$
\begin{aligned}
& 4 \mathrm{R}_{1}=\mathrm{R}_{2}=\mathrm{H} \\
& 5 \mathrm{R}_{1}=\mathrm{Me}, \mathrm{R}_{2}=\mathrm{H}
\end{aligned}
$$$$
6 \mathrm{R}_{1}=\mathrm{R}_{2}=\mathrm{Me}
$$

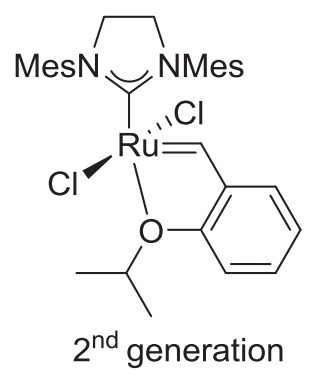

Hoveyda catalyst

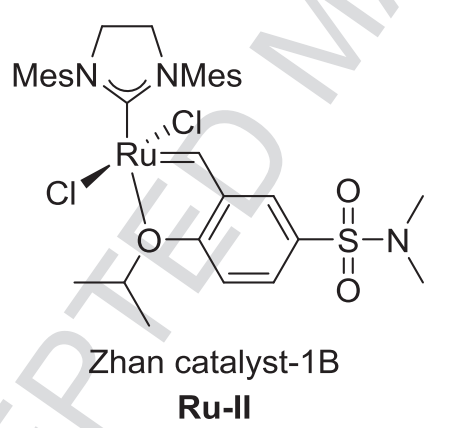

Ru-II

Ru-I

Scheme $1 \mathrm{RCM}$ in propylene carbonate (PC)

The RCM of $\mathbf{1}$ and $\mathbf{2}$ were conducted under experimental conditions established by Grubbs et al. for comparison of catalysts and processes performances.[32] As depicted in table 1, these transformations performed very well in propylene carbonate. If the efficiencies of catalyst Ru-I were slightly lower than those reported in dichloromethane (DCM), catalyst Ru-II was found more active in PC than in DCM (Table 1, entries 2, 3 and 5, 6). Without any catalyst solubility issue in PC and DCM, a rationale for this observation may be found in the molecular structure of catalyst Ru-II. One peculiarity of catalyst Ru-II is the presence of a polar and electron withdrawing sulfonamide group at the para-position of the coordinating isopropoxy ether. This sulfonamide substituent is intended to boost the initiation of the catalyst upon weakening the Ru-O bond. Hence, one hypothesis to explain the observed results may be found in the exaltation of the activating properties of the polar sulfonamide group in a very polar solvent. The reluctant RCM of $\mathbf{3}$ was conducted with higher catalyst loading $(2.5 \mathrm{~mol} \%)$ at $80{ }^{\circ} \mathrm{C}$ during $16 \mathrm{~h}$. Under these conditions moderate conversions (22$23 \%$ ) in agreement with modest results obtained with this type of catalysts were reached (Table 1, entries 7,8). For comparison a slightly better conversion of $36 \%$ was obtained in toluene under identical conditions with Ru-II (Table 1, entry 9). Altogether these three examples clearly demonstrated the compatibility of propylene carbonate for ruthenium 
catalyzed metathesis transformations. Nevertheless, extraction of polar compounds such as 46 was not easy and required multiple extractions with cyclohexane.

Table 1 RCM reactions in propylene carbonate

\begin{tabular}{|c|c|c|c|c|c|}
\hline Entry & Substrate & Cat & $t(\min )$ & Solvent & Conv. $(\%)^{\mathrm{c}}$ \\
\hline $1^{\mathrm{a}}$ & 1 & Ru-I & 30 & $\mathrm{PC}$ & $84(>95$ in DCM)[32] \\
\hline $2^{\mathrm{a}}$ & 1 & Ru-II & 30 & $\mathrm{PC}$ & 99 \\
\hline $3^{\mathrm{a}}$ & 1 & Ru-II & 30 & $\mathrm{DCM}$ & \\
\hline $4^{\mathrm{a}}$ & 2 & Ru-I & 60 & $\mathrm{PC}$ & $68(>95$ in DCM) [32] \\
\hline $5^{\mathrm{a}}$ & 2 & Ru-II & 60 & $\mathrm{PC}$ & 89 \\
\hline $6^{\mathrm{a}}$ & 2 & Ru-II & 60 & DCM & 55 \\
\hline $7^{\mathrm{b}}$ & 3 & Ru-I & $960(16 \mathrm{~h})$ & $\mathrm{PC}$ & 22 \\
\hline $8^{\mathrm{b}}$ & 3 & Ru-II & 960 & $\mathrm{PC}$ & 23 \\
\hline $9^{b}$ & 3 & Ru-II & 960 & toluene & 36 \\
\hline
\end{tabular}

The cross-metathesis of the renewable methyl undecenoate 7 [33] with functional olefin is an industrially relevant transformation since it provides an entry to bio-sourced polyester and polyamide monomers (Scheme 2).[34-35] We anticipated that product extraction that was found tedious with small polar olefins 4-6 should be facilitated by the more lipophilic character of $\mathbf{7}$ and its cross-metathesis products $\mathbf{8}$ and 9. If the cross-metathesis of $\mathbf{7}$ with acrylonitrile was not successful in PC, the cross-metathesis with methyl acrylate led to the expected diester 8. Careful investigation and optimization of the experimental parameters demonstrated that both catalysts Ru-I and Ru-II enabled high conversions at high temperature with low catalyst loading (Table 2) (see supplementary data). As observed in previous studies the reaction delivered the $E$-isomer as the major product.[34-35]

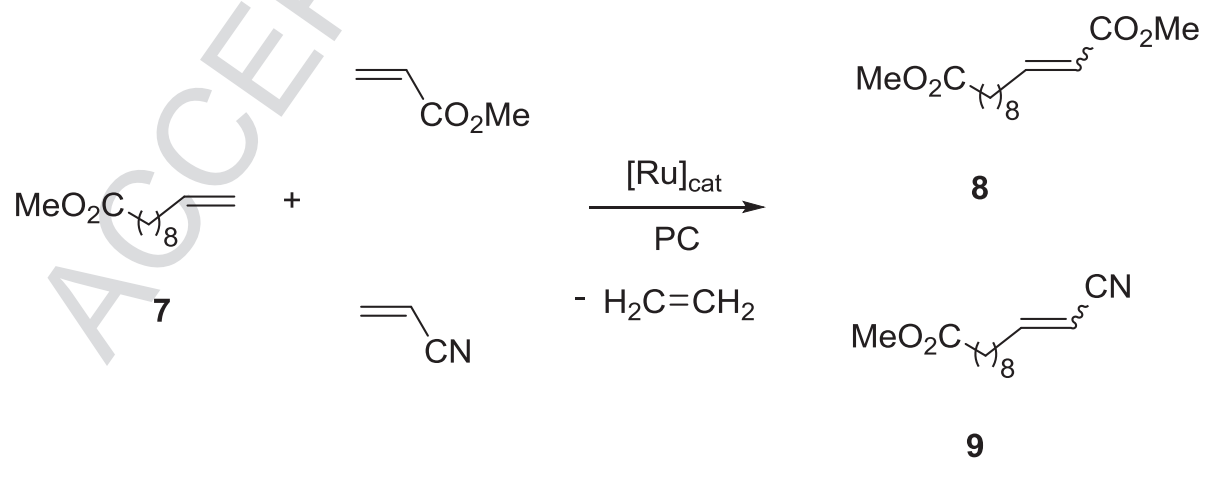

Scheme 2 CM of methyl undecenoate 7 with functional olefins in PC

Table $2 \mathrm{CM}$ of methyl undecenoate 7 with methyl acrylate in $\mathrm{PC}^{\mathrm{a}}$

\begin{tabular}{|c|c|c|c|c|c|c|}
\hline Entry & Cat (mol\%) & $\mathrm{T}\left({ }^{\circ} \mathrm{C}\right)$ & $\mathrm{t}(\mathrm{h})$ & [7] $\left(\mathrm{mol}^{\left.-L^{-1}\right)}\right.$ & Conv. $(\%)^{b}$ & $E / Z^{\mathrm{c}}$ \\
\hline 1 & Ru-II (0.5) & 50 & 3 & 0.5 & 9 & 7.0 \\
\hline 2 & Ru-II (0.5) & 80 & 3 & 0.5 & 46 & 6.2 \\
\hline 3 & $\mathbf{R u}-\mathbf{I}$ (1) & 100 & 3 & 0.5 & 96 & 7.1 \\
\hline 4 & Ru-II (1) & 100 & 3 & 0.5 & 97 & 6.8 \\
\hline 5 & Ru-I (0.5) & 80 & 15 & 1 & 98 & 7.9 \\
\hline
\end{tabular}


Having demonstrated the compatibility of propylene carbonate with Ru-catalyzed metathesis transformations, we have then evaluated the potential of TMS for the industrially relevant transformations of fatty acid methyl esters derivatives employing propylene carbonate as the polar phase and cyclohexane $(\mathrm{CH})$ as the non-polar component for the $\mathrm{CM}$ of 7 . Several semipolar solvents were evaluated of which ethyl acetate (EA) enabled best phase separation when reaction mixtures were cooled to room temperature. Initial tests were conducted in a $1 / 1 / 1$ mixture of $\mathrm{PC} / \mathrm{EA} / \mathrm{CH}$ at $80{ }^{\circ} \mathrm{C}$ with Zhan catalyst Ru-II $(0.5 \mathrm{~mol} \%)$. Interestingly, an improved conversion of $79 \%$ was obtained when compared to the same reaction conducted in pure propylene carbonate (conv. $46 \%$, Table 2, entry 2). The performance of the reaction and phase separation were slightly improved by using a 1/1/2 mixture of $\mathrm{PC} / \mathrm{EA} / \mathrm{CH}$. Under these conditions, a conversion of $88 \%$ was obtained. These results proved the suitability of a TMS system for olefin metathesis transformation. As anticipated, full recovery of the organic products was easier but still required 3 extractions with $5 \mathrm{~mL}$ of cyclohexane (c.a. $95 \%$ weight of product recovered). After solvent removal, the product was analyzed by ICP to evaluate the metal leaching from the PC phase. As suggested by the colorless color of the cyclohexane phase (see supplementary data), a very low metal leaching of $62 \mathrm{ppm}$ was measured in the reaction product (theoretical content $\sim 2500 \mathrm{ppm}$ ). Further quick filtration on a short plug of silica ( $\mathrm{h} \times \mathrm{d}=2 \mathrm{~cm} \times 1 \mathrm{~cm}$ ) and elution with petroleum ether/ethyl acetate $(1 / 1, v / v)$ was sufficient to lower the ruthenium content below $1 \mathrm{ppm}$. This flash filtration was also efficient in removing low amounts of propylene carbonate (c.a. 5-10\%) that was found in the cyclohexane extracts. These encouraging results but also the drawbacks of this process related to product recovery prompted us to search for an alternative solvents composition. In particular, we foresaw that 7 featuring an aliphatic chain and a polar ester group could act as a suitable semi-polar solvent. Hence, preliminary experiments were conducted and proved that 7 could indeed be used as the semi-polar solvent. Replacing ethyl acetate by 7 was also expected to have a beneficial impact on the reaction outcome since higher reagent concentration is known to improve the efficacy of cross-metathesis reactions with methyl acrylate.[35] Thus, the cross-metathesis of 7 carried out with a solvent composition $\mathrm{PC} / 7 / \mathrm{CH}$ $0.6 \mathrm{ml} / 1 \mathrm{~mL} / 0.6 \mathrm{~mL}$ reached $97 \%$ conversion in $3 \mathrm{~h}$ (Table 3 , entry 1 ). It must be mentioned that after $3 \mathrm{~h}$, the reaction mixture was still monophasic and biphasic when cooled down to room temperature demonstrating that product $\mathbf{8}$ was also playing the role of semi-polar solvent. Finally, the performances ot the catalytic system were further improved by using the slow addition of catalyst method.[35] As depicted in Table 3, high conversion was maintained with a catalyst loading as low as $0.25 \mathrm{~mol} \%$ (entry 2 ).

Table 3 Dual role of $7^{\text {a }}$

\begin{tabular}{|c|c|c|c|c|}
\hline Entry & Cat (mol\%) & $\mathrm{t}(\mathrm{h})$ & Conv. $(\%)^{b}$ & $E / Z^{\mathrm{c}}$ \\
\hline 1 & 0.5 & 3 & $97(91)^{d}$ & 8.1 \\
\hline 2 & 0.25 & $2+1^{\mathrm{e}}$ & 93 & 8.9 \\
\hline \multicolumn{5}{|c|}{$\begin{array}{l}{ }^{\mathrm{a}} 7(4.5 \mathrm{mmol}) \text {, methyl acrylate }(9 \mathrm{mmol}, 2 \text { equiv), propylene carbonate }(0.6 \\
\mathrm{mL}) \text {, cyclohexane }(0.6 \mathrm{~mL}) \text {, catalyst Ru-II, } 80{ }^{\circ} \mathrm{C} \text {. }{ }^{6} \text { Determined by gas } \\
\text { chromatography using tetradecane as internal standard. }{ }^{\mathrm{c}} \text { determined by }{ }^{1} \mathrm{H} \\
\text { NMR. isolated yield. }{ }^{\text {e }} \text { catalyst dissolved in propylene carbonate and added over } \\
\text { a period of } 2 \text { hours. The reaction was further stirred for } 1 \mathrm{~h} \text { at } 80{ }^{\circ} \mathrm{C} \text {. }\end{array}$} \\
\hline
\end{tabular}

Initial experiments showed that cross-metathesis reactions with acrylonitrile were not operating in pure propylene carbonate. To the contrary of cross-metathesis with methyl acrylate, cross-metathesis with acrylonitrile requires diluted conditions.[35] Consequently, a TMS system employing 7 as the semi-polar solvent is not best suited for cross-metathesis reactions with acrylonitrile and an initial solvent composition $(\mathrm{PC} / \mathrm{EA} / \mathrm{CH})$ was used to study 
this transformation. We were pleased to find that cross-metathesis of 7 with acrylonitrile was possible upon employing this TMS system. We then optimized the experimental parameters in order to reach high conversion and product recovery. As summarized in Table 4, best results were obtained with catalyst $\mathbf{R u}-\mathbf{I I}$ at $100{ }^{\circ} \mathrm{C}$ under high dilution conditions (Entry 5). $1 \mathrm{~mol} \%$ of catalyst was required to ensure high conversion indicating that this transformation does not perform with the same efficiency as under classical solvent conditions (i.e. 95\% conv. was obtained in $1 \mathrm{~h}$ at $80{ }^{\circ} \mathrm{C}$ in toluene with $1 \mathrm{~mol} \%$ of $\mathbf{R u}-\mathbf{I}$ and [7] $=0.05$ mol.L $\mathrm{L}^{-1}$ [35]). However, product separation from the residual catalyst required a simple phase separation and as mentioned in previous examples, 3 extractions with cyclohexane were necessary to ensure full recovery of the reaction product.

Table 4 Cross-metathesis of 7 with acrylonitrile ${ }^{\mathrm{a}}$

\begin{tabular}{|c|c|c|c|c|c|c|}
\hline Entry & Cat (mol\%) & $\mathrm{T}\left({ }^{\circ} \mathrm{C}\right)$ & $\mathrm{t}(\mathrm{h})$ & [7] $\left(\mathrm{mol} \cdot \mathrm{L}^{-1}\right)$ & Conv. $(\%)^{b}$ & $Z / E^{\mathrm{c}}$ \\
\hline 1 & $\mathbf{R u}-\mathbf{I}(1)$ & 80 & 3 & 0.05 & 20 & 2.6 \\
\hline 2 & Ru-II (1) & 80 & 3 & 0.05 & 27 & 2.5 \\
\hline 3 & Ru-II (1) & 80 & 3 & 0.025 & 57 & 4.2 \\
\hline 4 & Ru-II (1) & 80 & 3 & 0.01 & 79 & 8.2 \\
\hline 5 & Ru-II (1) & 100 & 3 & 0.01 & $87(80)^{\mathrm{d}}$ & 2.7 \\
\hline 6 & Ru-II (0.5) & 100 & 3 & 0.01 & 34 & 5.9 \\
\hline
\end{tabular}

\section{Conclusion}

We have investigated the compatibility, potential and limitations of TMS systems employing propylene carbonate as the polar solvent in a series of olefin metathesis transformations including cross-metathesis of renewable substrates of interest for the synthesis of bio-sourced monomers. We have established that these metathesis transformations performed with high efficiency in most cases and that catalyst residues remained immobilized in propylene carbonate ensuring low contamination of the cross-metathesis product (62 ppm in the crude product and $<1 \mathrm{ppm}$ after flash filtration on a short plug of silica for the cross-metathesis of methyl undecenoate with methyl acrylate). We have identified one drawback that concerns product extraction and recovery in particular with small polar products such as 4, 5, 6 . Product recovery was easier with the more lipophilic compounds resulting from crossmetathesis of 7. TMS systems therefore constitute promising processes for application in olefin metathesis but further efforts aimed at identifying other solvent combinations will be necessary to improve and facilitate product recovery.

\section{Acknowledgement}

The authors are grateful to the French-Tunisian joint project PHC-UTIQUE n 09G1203 for financial support to HB. We acknowledge B. Lefeuvre (OMC, Multifunctional Inorganic Materials) for ICP measurements.

Keywords: Olefin metathesis, Thermomorphic solvent system, ruthenium, renewables

\section{References}

[1] R. H. Grubbs, Handbook of metathesis, Wiley-VCH: Weinheim. Germany 2003

[2] A. H. Hoveyda, A. R. Zhugralin, Nature (450) 2007243

[3] S. Shahane, C. Bruneau, C. Fischmeister, ChemCatChem (5) 20133436

[4] G. C. Vougioukalakis, R. H. Grubbs, Chem. Rev. (110) 20101746 
[5] E. Colacino, J. Martinez, F. Lamaty, Coord. Chem. Rev. (251) 2007726

[6] A. Gradillas, J. Pérez-Castells, Angew. Chem. Int. Ed. (45) 20066086

[7] G. C. Vougioukalakis, Chem. Eur. J. (18) 20128868

[8] H. Clavier, K. Grela, A. Kirschning, M. Mauduit, S. P. Nolan, Angew. Chem. Int. Ed. (46) 20076786

[9] D. Sémeril, H. Olivier-Bourbigou, C. Bruneau, P. H. Dixneuf, Chem. Commun. 2002146

[10] Sz. Csihony, C. Fischmeister, C. Bruneau, I. T. Horváth, P. H. Dixneuf, New J. Chem. (26) 20021667

[11] N. Audic, H. Clavier, M. Mauduit, J.-C. Guillemin, J. Am. Chem. Soc. (125) 20039248

[12] Q. Yao, Y. Zhang, J. Am. Chem. Soc. (126) 200474

[13] A. Fürstner, L. Ackermann, K. Beck, H. Hori, D. Koch, K. Langemann, M. Liebl, C. Six, W. Leitner, J. Am. Chem. Soc. (123) 20019000

[14] A. Keraani, T. Renouard, C. Fischmeister, C. Bruneau, M. Rabiller-Baudry, ChemSusChem (1) 2008927

[15] G. Nasser, T. Renouard, S. Shahane, C. Fischmeister, C. Bruneau, M. Rabiller-Baudry, ChemPlusChem (78) 2013728

[16] X. Miao, C. Fischmeister, C. Bruneau, P. H. Dixneuf, ChemSusChem (1) 2008813

[17] D. E. Bergbreiter, Y.-S. Liu, P. L. Osburn, J. Am. Chem. Soc. (120) 19984250

[18] A. Behr, N. Toslu, Chem. Ing. Tech. (79) 1999490

[19] A. Behr, B. Turkowski, R. Roll, R. Schöbel, G. Henze, Top Organomet Chem (23) 2008 19

[20] A. Behr, G. Henze, R. Schomäcker, Adv. Synth. Catal. (348) 20061485

[21] Y. Brunsch, A. Behr, Angew. Chem. Int. Ed. (52) 20131586

[22] A. Behr, L. Johnen, A. Vorholt, ChemCatChem (2) 20101271

[23] A. Behr, T. Seidensticker, A. J. Vorholt, Eur. J. Lipid Sci. Technol. (116) 2014, 477

[24] A. Behr, A. J. Vorholt, N. Rentmeister, Chem. Eng. Sci. (99) 201338

[25] D. E. Bergbreiter, C. Hobbs, C. Hongfa, J. Org. Chem. (76) 2011523

[26] A. Behr, J. Gomes-Jelonek, H. Witte, Chem. Ing. Tech. (84) 20122174

[27] H-L Su, C. Hongfa, H. S. Bazzi, D. E. Bergbreiter, Macromol. Symp. (297) 2010, 25

[28] C. Hobbs, Y.-C. Yang, J. Ling, S. Nicola, H.-L. Su, H. S. Bazzi, D. E. Bergbreiter, Org. Lett. (13) 20113904

[29] H. Bilel, N. Hamdi, F. Zagrouba, C. Fischmeister, C. Bruneau, RSC Adv. (2) 20129584

[30] A. Dupé, M. Achard, C. Fischmeister, C. Bruneau, ChemSusChem (5) 20122249

[31] For a review on carbonate solvents, see: B. Schäffner, F. Schäffner, S. P. Verevkin, A. Börner, Chem. Rev. (110) 20104554

[32] T. Ritter, A. Hejl, A. G. Wenzel, T. W. Funk, R. H. Grubbs, Organometallics (25) 2006 5740

[33] M. Van der Steen, C. V. Stevens, ChemSusChem (2) 2009692

[34] A. Rybak, M. A. R. Meier, Green Chem. (9) 20071356

[35] X. Miao, R. Malacea, C. Fischmeister, C. Bruneau, P. H. Dixneuf, Green Chem. (13)

20112911 
Highlights

- We have performed ruthenium catalyzed olefin metathesis in pure propylene carbonate

- We have performed Ru-catalyzed olefin metathesis in Thermomorphic Solvent system

- Renewable methyl undecenoate was transformed in TMS system

- Low metal contamination was detected by ICP 